\title{
The effect of rubber powder additives on mechanical properties of polypropylene glass-fiber-reinforced composite
}

\author{
Abdelaal M. Elhousari ${ }^{1}$, Maher Rashad ${ }^{1}$, Ammar H. Elsheikh ${ }^{1}$, and Montasser Dewidar ${ }^{2,3}$ \\ ${ }^{1}$ Production Engineering and Mechanical Design Department, Tanta University, Tanta 31527, Egypt \\ ${ }^{2}$ Department of Mechanical Engineering, Faculty of Engineering, \\ Kafereksheikh University, Kafrelsheikh 33516, Egypt \\ ${ }^{3}$ Higher Institute of Engineering and Technology, Kafrelsheikh 33516, Egypt
}

Correspondence: Ammar H. Elsheikh (ammar_elsheikh@f-eng.tanta.edu.eg)

Received: 23 November 2020 - Revised: 16 January 2021 - Accepted: 11 March 2021 - Published: 30 April 2021

\begin{abstract}
Reinforced thermoplastic composites offer considerable advantages in structural and industrial applications in terms of high specific strength, excellent corrosion resistance, high impact toughness, high specific stiffness, recyclability, cost effectiveness, and design flexibility. Glass fibers (GFs) are the reinforcement material used in polypropylene (PP) composites to enhance PP properties with reasonable cost. To obtain better mechanical properties and decrease the overall cost, recycled rubber powder was used as a low-cost additive to PP/GF composites. The PP and GF, with different weight fractions, were mixed mechanically; then, the mixture was fed into injection molding machine. The PP/GF composites with the highest mechanical properties were selected for further improvements using rubber powder. The obtained samples were tested using tension, impact, and wear tests. The results show that tensile strength of PP/GF composite was improved by $17.8 \%$ by adding $15 \mathrm{wt} \% \mathrm{GF}$, and there was a huge drop in impact strength by $80 \%$ for the same GF weight fraction (15 wt \%) compared to that of pure PP because of existence of GF. Wear properties and impact strength were improved by adding rubber powder to the composite, with a low weight fraction of $5 \mathrm{wt} \%$, due to the shock-absorbing properties of rubber powder. Micrographs of the fractured sample surfaces revealed the good adhesion between the GF, PP, and the rubber particles.
\end{abstract}

\section{Introduction}

Polymeric materials have been widely used in various engineering applications due to their superior advantages over the other materials, such as excellent chemical resistance, excellent electrical and thermal insulating characteristics, good abrasion resistance, high specific strength, sufficient hardness, low moisture absorption, and ease of processing (Elsheikh et al., 2020b; Khoshaim et al., 2021b). Polymeric materials have been used in various industries, including biomedical, semiconductor, aerospace, and automotive (Babikir et al., 2019; Kamal et al., 2020). Polypropylene (PP) is second most commonly used polymer in industrial applications such as vehicles, marine industries, bicycles, civil necessities, electronic products, and medical instru- ments in form of chemical tanks, pipes, and sheets (Elsheikh et al., 2019a; Pasquini and Addeo, 2005; Rathod et al., 2017; Showaib and Elsheikh, 2020). PP suffers from low mechanical properties which limit its usage (Lin et al., 2015; Yimit et al., 2018). Therefore, it was recommended to add different reinforcement materials to PP to form enhanced composite materials (Abdellah et al., 2018; Dewidar et al., 2010). It is well known that composite materials are a combination of two materials with different physical and chemical properties, which have been extensively investigated in the literature (Elsheikh et al., 2020c; Essa et al., 2021; Fadl et al., 2019; Liu et al., 2020; Wang and Fu, 2019; Xu et al., 2017). The glass-fiber-reinforced PP has been considered as a lightweight and cost-effective composite used in automotive and marine industries (Luo et al., 2018; Rahman et al., 
2013; Xu et al., 2019). Other particulate fillers, such as silica (Pustak et al., 2016), coir fiber (Ayrilmis et al., 2011), aramid fibers (Ovcharenko and Bashtannik, 1996), rice husk (Raghu et al., 2018), wood fiber (Huang et al., 2018), sisal, banana, jute, and flax (Oksman et al., 2009) have been used to augment the mechanical properties of PP, such as the stiffness, hardness, and strength. Among all synthetic fibers used in preparing fiber-reinforced PP composites, glass fibers are the most used reinforcement in PP-based composites. E-glass/PP composites have been reported as being an enhanced composite with good mechanical properties (Santulli et al., 2002). On the other hand, for natural fibers, flax fibers have shown good mechanical properties when reinforced with PP (Strapasson et al., 2005). To obtain better mechanical properties from the produced composites, preprocessing and treatment techniques such as oxidation, alkalization and/or mercerization, and diazotization should be applied on the fibers (Shubhra et al., 2013). These techniques help in improving adhesion between PP and fibers, which consequently enhances the mechanical strength of the produced composites. The interfacial adhesion between wood fibers (bleached kraft pulp of eucalyptus) and PP was enhanced by treating the PP using m-isopropenyl- $\alpha$ and $\alpha$-dimethylbenzyl isocyanate grafted polypropylene (Karmarkar et al., 2007). Despite the hydrophilic nature of wood fibers and the hydrophobic nature of PP, the proposed preprocessing technique improved the interfacial adhesion between wood fibers and PP. Mechanical techniques have been also applied to obtain natural fibers using eco-friendly techniques. A full-scale mechanical manufacturing system for the production of rice straw fibers was designed and established in El-Kassas and Elsheikh (2020). The produced rice straw fibers were used as an alternative raw material for the manufacturing of medium-density fiberboards.

Many investigations have been carried out to explore the benefits of using glass fiber as a reinforcement filler in PPbased composites. The mechanical performance and fracture mechanisms of glass-fiber-reinforced PP was evaluated by Barré and Benzeggagh (1994). The use of nanoclay in glass-fiber-reinforced PP composites, prepared by injection molding and twin-screw-extruding techniques, was studied by Rahman et al. (2012). Palza et al. (2011) used the solgel method to synthesize silica nanoparticles, which blended with PP to obtain an enhanced PP-based composite. However, increasing the concentration of nanoparticles resulted in formation of an undesirable agglomeration, which consequently impaired the mechanical properties of the produced composite. The properties of the hybrid carbon-nanotubecoated carbon fiber PP composite were investigated by Shazed et al. (2014). It was reported that incorporating glass fibers into PP could decrease the glass transition temperature (Rahman et al., 2013). Etcheverry and Barbosa (2012) proposed a new in situ polymerization method of PP onto glass fibers to enhance the adhesion between them. This method involves the treatment of fibers with a hydroxy- $\alpha$-olefin and aluminum alkyl, followed by metallocenic copolymerization. Pozzi et al. (2010) used fibers produced from the recycled cathode ray tube glasses as a filler in a polypropylene-based composite. The recycled fibers are used as a low-cost alternative to commercial glass fibers. The PP was treated using maleic anhydride to improve interfacial bonding.

A ternary PP-based composite has been proposed as a good alternative to the conventional dual composite. A hybrid filler, consisting of aminosilane-treated hollow glass beads and short GF, was used as a reinforcement material in a ternary PP-based composite (Carvalho et al., 2020). Nanosilica and GF were incorporated to produce a ternary PP-based composite prepared by a twin screw extrusion and injection molding technique (Rasana and Jayanarayanan, 2018). Well-arranged glass fibers, surrounded by nanosilica, were observed in the obtained microstructure, which resulted in augmenting the modulus and the tensile strength of the hybrid composite. It was reported that the presence of glass fibers could accelerate the PP crystallization better compared to nanosilica. Confinement regions, generated from the incorporation between micro- and nanofillers, were observed, which delayed the solvent diffusion in the developed composite. Hybrid carbon-GF/PP composites were prepared using compression molding and two-roll-milling machine techniques (Padhi and Sahoo, 2019). The strength initially decreased by increasing the weight fraction of the carbon fiber, and then it increased with the addition of more carbon fibers. On the other hand, the toughness of the developed composite gradually decreased by increasing the weight fraction of the carbon fiber.

The influence of a hybrid multiscale filler consisting of glass fibers, with micro sizes and multiwalled carbon nanotubes with nano sizes, on the mechanical properties and the thermal degradation of PP were explored by Rasana et al. (2019). Mohan and Kanny (2010) investigated the effect of the incorporation of nanoclay and short GF as a hybrid filler on the structure and the mechanical properties of PPbased composites. The use of nanoclay resulted in a significant reduction in the flow rate of melted PP; however, it augmented the crystallization characteristics thanks to the nano-level dispersion of nanoclay in the polymer matrix. The tensile strength of the developed composite has been also increased due to the obtained exfoliated and/or intercalated structure.

Hybrid composites of PP/GF and nanoclay were prepared by extrusion and injection molding (Morfologi and dan Mekanik, 2013). Layered nanoclay was applied as a nanoscale filler in GF-reinforced PP composites. The potential synergistic effects and functional advantages of GF and nanoclay were exploited to enhance the mechanical properties of PP. For PP/GF composites, the tensile modulus, flexural modulus, and flexural strength increased, while tensile strength decreased with increased fiber loading. The use of nanoclay particles improved the mechanical properties of the developed composite. The mechanical properties of graphite- 
fiber-reinforced PP composites produced by compression and injection molding were investigated in Weiss (1981). The tensile strength of the produced composites was improved compared with GF reinforcement. The effects of using silica, carbon black, and calcium carbonate as fillers in PP, natural rubber, or recycled rubber composites were investigated in Ismail and Suryadiansyah (2004). The elasticity modulus and tensile strength increased with the increased silica and carbon black content in PP-rubber composites, while calcium carbonate showed the opposite trend, except for the modulus of elasticity. The swelling percentage of the carbon-blackreinforced PP-rubber composites is highest among all developed composites, followed by calcium carbonate and silica, and it increased with time.

In this study, PP is reinforced by GF, and recycled rubber powder was used as an inexpensive filler to improve the mechanical properties of the PP/GF composite. The microstructure of the developed composites was examined using a scanning electron microscope (SEM). The mechanical properties were explored using the tension test, impact test, and wear test.

\section{Experimental work}

\subsection{Materials}

PP with a melt flow index of $3.7 \mathrm{~g}$ per $10 \mathrm{~min}$ at $230^{\circ} \mathrm{C}$, according to ASTM D1238-13 (a standard test method for melt flow rates), was supplied by SABIC in Cairo, Egypt. Rubber particles, with an average size of $1 \mathrm{~mm}$, were supplied by KMC Engineering Company in Sharkia, Egypt. E6 glass fiber, with a filament diameter of $14 \mu \mathrm{m}$ and a length of 10 $20 \mathrm{~mm}$, was used as reinforcement in the developed PP composite and was supplied by China Jushi Co., Ltd. in Chengdu, China. The properties of the used materials are listed in Table 1, and photos of them are shown in Fig. 1.

\subsection{Sample preparation}

PP obtained from SABIC was crushed by a mechanical crusher into grains of $0.5 \times 0.5 \mathrm{~cm}$ size, and dried carefully in the open air for $2 \mathrm{~h}$, then mixed manually with GF of $40 \mu \mathrm{m}$ thickness and 10-20 mm length, with five weight fractions ( $2 \mathrm{wt} \%-20 \mathrm{wt} \%)$. The produced samples are PP/GF2, PP/GF5, PP/GF10, PP/GF15, and PP/GF20. After mixing, the obtained mixture was fed into the hopper of the extruder and heated. The test samples were prepared according to ASTM D638 (a method for testing the tensile strength of plastics and other resin materials) standards, using an injection molding machine (PL1200; Haitian International Holdings Limited) with a maximum clamping force of $1200 \mathrm{kN}$. The barrel temperature profile along the injection molding machine was adjusted to be $140,160,180,190$, and $200^{\circ} \mathrm{C}$. Table 1 shows the conditions of operating machine compared to the manufacture specimens. Rubber powder, obtained by grinding recycled rubber tire to $1 \mathrm{~mm}$ in size, was added with three weight fractions ( $5 \mathrm{wt} \%, 10 \mathrm{wt} \%$, and $20 \mathrm{wt} \%$ ) to previous mixtures to produce new composites. The rubber powder was added as reinforcement for the PP/GF with the highest mechanical properties (PP/GF10 and PP/GF15). The produced samples are PP/GF10 R5, PP/GF10 R10, PP/GF10 R20, PP/GF15 R5, PP/GF15 R10, and PP/GF15 R20.

\subsection{Testing \\ 2.3.1 Tensile test}

Tensile tests were carried out on computerized universal testing machine (model HLC-150), according to ASTM D638 standards, using a cross-head speed of $5 \mathrm{~mm}$ per minute at room temperature. The machine is controlled using a computerized automatic control system, and it has a maximum load of $300 \mathrm{kN}$. The machine has a deformation accuracy indication of $\leq \pm 0.5 \%$. The test specimens were cut into $7.3 \mathrm{~mm}$ diameter. The machine pulls the sample until a failure occurs. The force that was applied to the sample until failure occurred was recorded. A total of five specimens were tested for each composition, and the average value was calculated. For each prepared composite type, five tensile specimens were tested, and the average value of modulus of elasticity, tensile strength, and maximum elongation was computed.

\subsubsection{Charpy impact test}

Charpy impact tests were carried out on un-notched specimens $(10 \mathrm{~mm} \times 5 \mathrm{~mm} \times 90 \mathrm{~mm})$, using a 420D series digital Charpy impact tester, according to ASTM D4812 standards, at $25^{\circ} \mathrm{C}$. The maximum capacity of the machine is $25 \mathrm{~J}$, while the used energy during the testing of specimens was $10 \mathrm{~J}$. A total of five replicates were used for each prepared composite type, and the average value of the response was computed. The Charpy specimen was prepared according to ASTM standards with the following dimensions: the specimen length was $125 \mathrm{~mm}$ and the cross-sectional area was $10 \mathrm{~mm} \times 12.7 \mathrm{~mm}$. The notch had a depth of $2.54 \mathrm{~mm}$, with a $45^{\circ}$ angle and $0.25 \mathrm{~mm}$ tip radius.

\subsubsection{Wear test}

Wear tests were carried out at room temperature, according to ASTM G99 (test method for wear testing) standards, on a pin-on-disc test rig in which a rotary horizontal disc $(5 \mathrm{~mm}$ thickness and $170 \mathrm{~mm}$ diameter) is driven by a motor. Composite specimens were cut into small rectangular specimens, with a length of $90 \mathrm{~mm}$, a width of $10 \mathrm{~mm}$, and a height of $5 \mathrm{~mm}$. The prepared specimens were held in the pin holder and loaded against a rotating abrasive sheet (grade A600) fixed on the rotating disc. Due to the adhesion between composites and the abrasive sheet, the resistance force tries to resist the rotating disc. This force depends on the friction 
Table 1. Material properties.

\begin{tabular}{llrrlr}
\hline & Material type & $\begin{array}{r}\text { Density } \\
(\mathrm{g} / \mathrm{cc})\end{array}$ & $\begin{array}{r}\text { Tensile strength } \\
(\mathrm{MPa})\end{array}$ & $\begin{array}{r}\text { Average size } \\
\text { Poisson } \\
\text { ratio }\end{array}$ \\
\hline Polypropylene & Copolymer & 0.91 & 28 & Grains $(5 \mathrm{~mm})$ & 0.36 \\
Fiberglass & E-fiberglass & 2.60 & 2000 & Fibers $(10-20 \mathrm{~mm})$ & 0.21 \\
Rubber powder & Recycled rubber & 1.52 & 45 & Particles $(1 \mathrm{~mm})$ & 0.49 \\
\hline
\end{tabular}

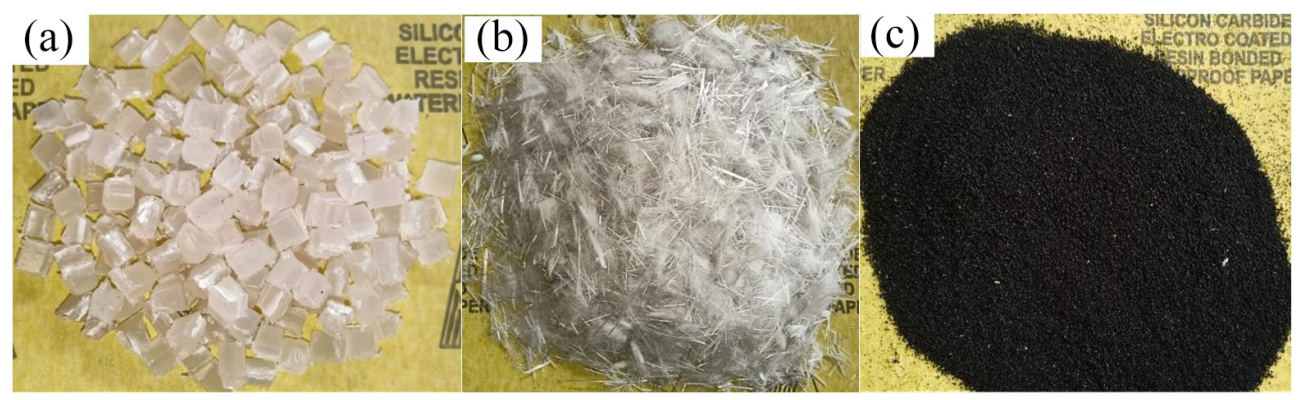

Figure 1. Photos of the used materials. (a) Polypropylene. (b) Fiberglass. (c) Rubber powder.
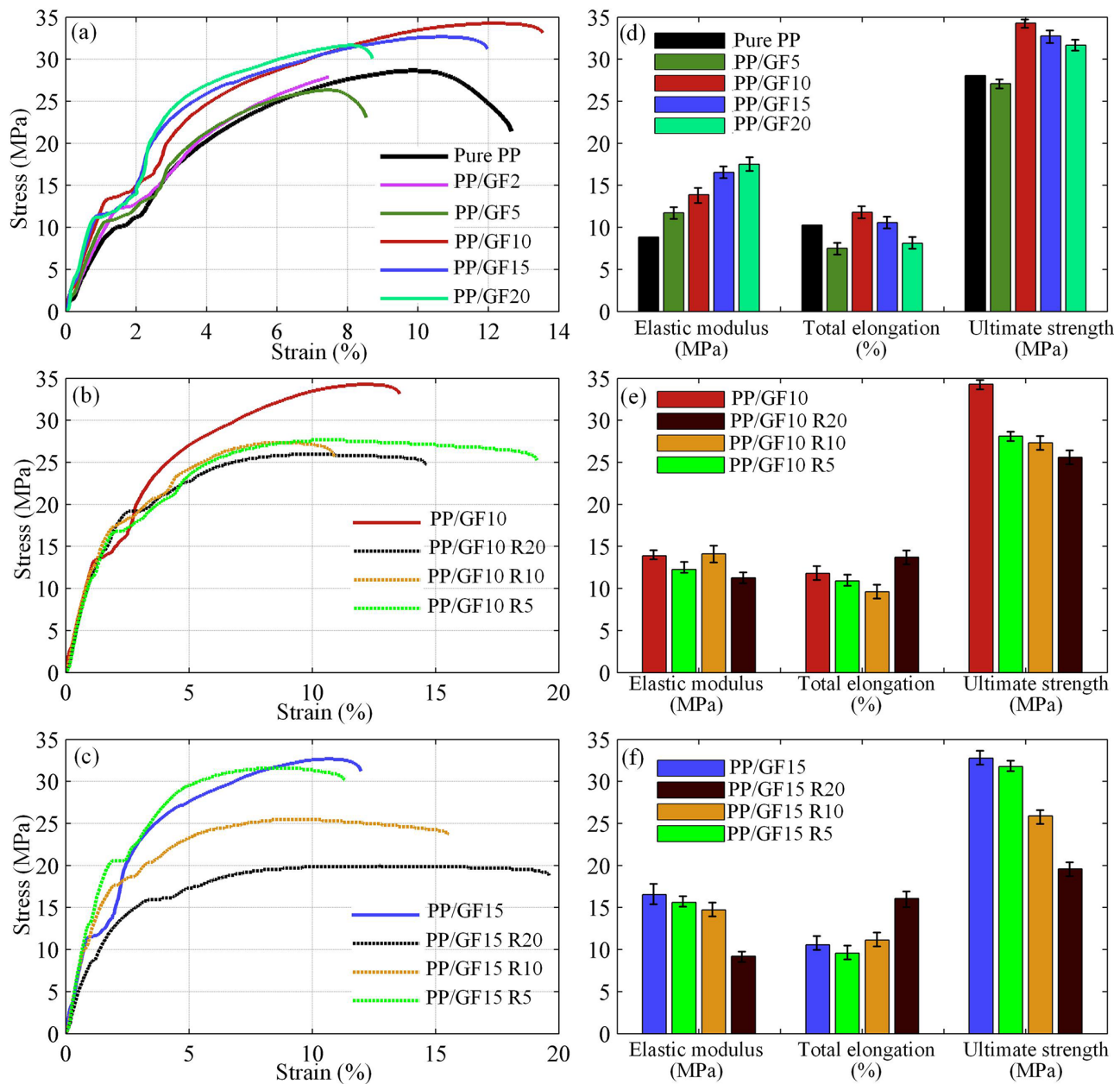

Figure 2. Stress-strain curves and mechanical properties of pure PP, PP/GF, and PP/GF R (rubber powder) composites. 


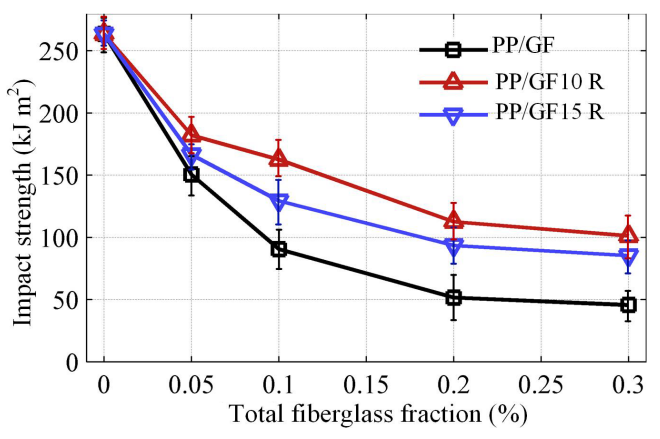

Figure 3. Impact strength of the composite.

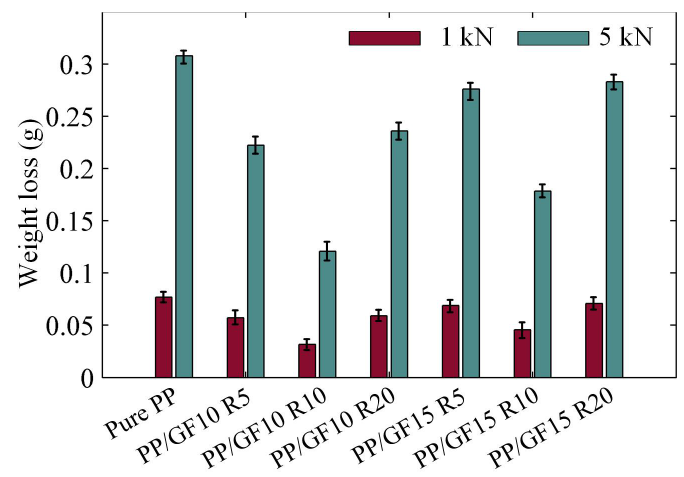

Figure 4. Weight loss variation under different normal loads, with different content of GF and rubber powder in the composite.

coefficient of composites. The experiments were carried out at $60 \mathrm{rpm}$ (revolutions per minute) under two different loads ( 1 and $5 \mathrm{~kg}$ ). Wear was computed by measuring the change in composite volume before and after adhesion between the composites and the abrasive sheet counterface for $60 \mathrm{~min}$ at $20 \mathrm{~N}$ normal load and a counterface rotational speed of $60 \mathrm{rpm}$.

Wear $=\Delta V=\left(L_{1}-L_{2}\right) A$,

where $L_{1}$ and $L_{2}$ denote specimen length before and after the test, respectively, in millimeters, and $A$ is the interface area between the specimen and the abrasive sheet.

\subsubsection{Morphology}

The morphology of the composite surface was explored using a JSM-IT100 scanning electron microscope (SEM). The resolution of the used microscope is $4.0 \mathrm{~nm}(20 \mathrm{kV})$ at highvacuum mode and $5.0 \mathrm{~nm}(20 \mathrm{kV})$ at low-vacuum mode, with a wide range of magnification ( $x 5$ to $x 300000$ ). The prepared samples were coated with a thin layer of gold by using a sputter coater (model Dll-29030SCTR; Smart Coater).
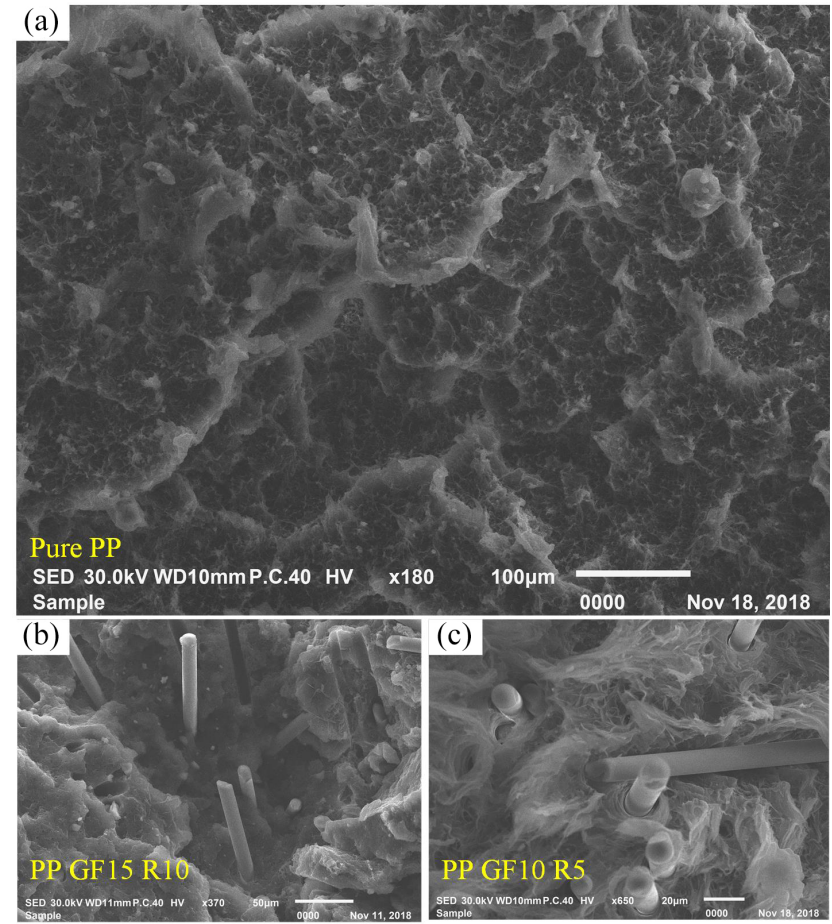

Figure 5. SEM images. (a) Pure PP. (b) PP/GF15 R10. (c) PP/GF10 R5.

\section{Results and discussion}

\subsection{Tensile test}

For each composition PP composite, including pure PP, five samples were tested on the universal testing machine. The average values of the mechanical properties obtained from the stress-strain curve were calculated. The stress strain curves of the pure PP and PP/GF composite, with different contents of GF $(2 \%, 5 \%, 10 \%, 15 \%$, and $20 \%)$ are shown in Fig. $2 \mathrm{a}$ and d. For composite specimens with a low GF content, the ultimate tensile strength was decreased. Then, increasing the GF content resulted in increasing the ultimate strength, which reached its peak value for PP/GF10. After that, increasing the GF content more than $10 \%$ resulted in decreasing the ultimate tensile strength. Therefore, it could be concluded that PP/GF10 and PP/GF15 have the highest ultimate strength among all investigated PP/GF composites. The ultimate tensile strength was mostly increased to $34 \mathrm{MP}$ in case of PP/GF10, which is higher than that of pure PP by about $21 \%$. The same trend was observed for total elongation, as PP/GF10 had the highest total elongation, followed by PP/GF15. The total elongation of PP/GF10 is higher than that of pure PP by about $15 \%$. On the other hand, the modulus of elasticity of PP/GF composites is directly proportional to the GF content, and consequently, PP/GF20 has the highest modulus of elasticity. The modulus of elasticity of PP/GF20 is higher than that of pure PP by about $98 \%$. There- 

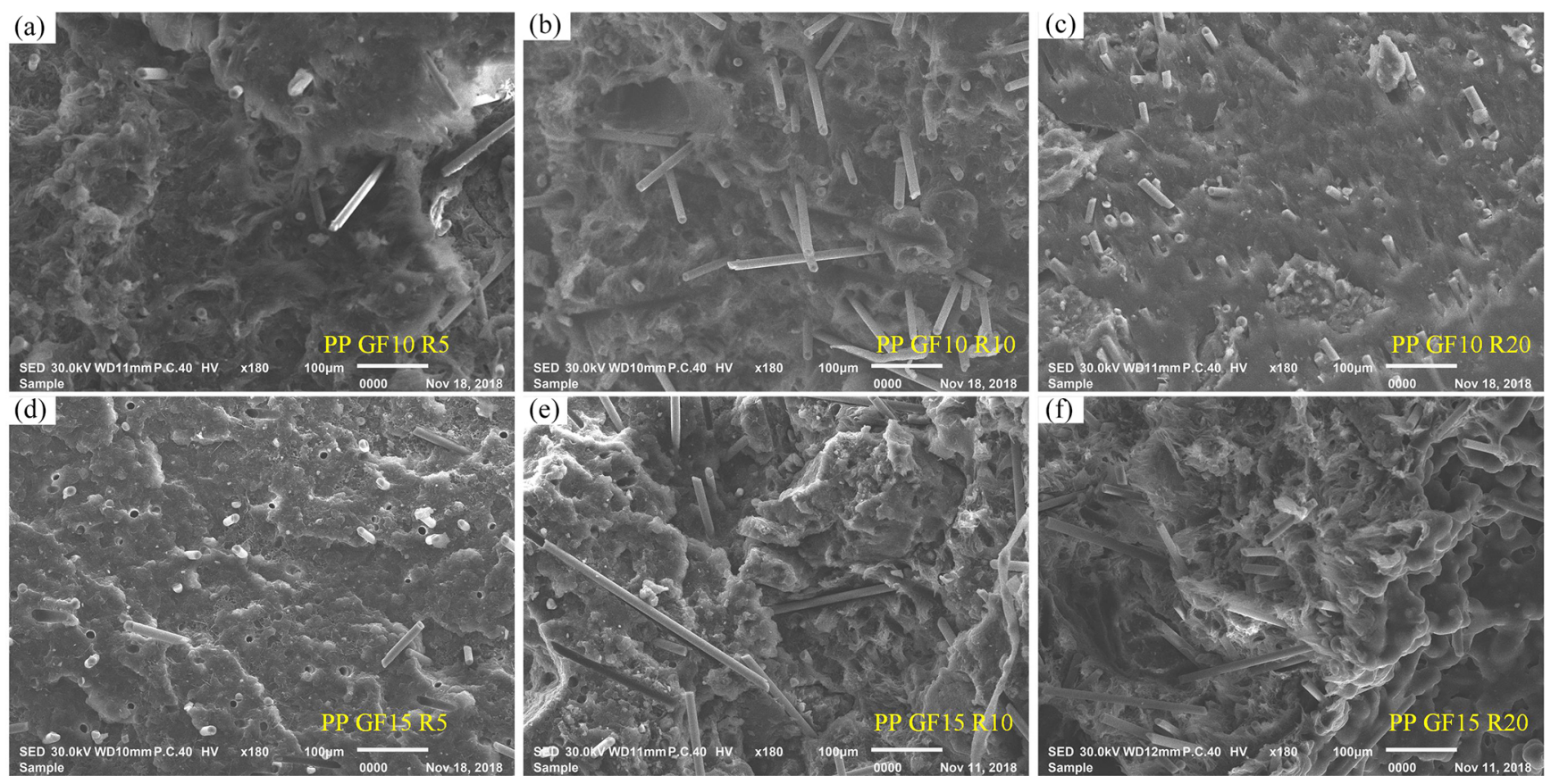

Figure 6. SEM images. (a) PP/GF10 R5. (b) PP/GF10 R10. (c) PP/GF10 R20. (d) PP/GF15 R5. (e) PP/GF15 R10. (f) PP/GF15 R20.

fore, PP/GF10 and PP/GF15 have been selected for further investigation to explore the effect of using rubber powder as a reinforcement additive on PP/GF properties. For PP/GF10 and PP/GF15, the ultimate tensile strength is decreased by adding rubber powder compared with rubber-free GF composites; however, it still higher than that of pure PP, as shown in Fig. 2c-f. The same trend is observed for modulus of elasticity. The total elongation of rubber-based composites is increased by increasing the rubber content. It is increased by about $16 \%$ and $52 \%$ for PP/GF10 P20 and PP/GF15 P20, respectively, compared with that of PP/GF10 and PP/GF15, respectively. As a conclusion, GF could be used to enhance the mechanical properties of PP, and rubber powder could be used to enhance the elongation of the developed composite with fewer side effects on the ultimate tensile strength. Moreover, it is recommended to apply advanced machine learning techniques, such as the artificial neural network (Elsheikh et al., 2020a, 2019b; Khoshaim et al., 2021a), support vector machine (El-Said et al., 2021), long short-term memory network (Elsheikh et al., 2021; Saba and Elsheikh, 2020), adaptive neuro-fuzzy inference system (Elaziz et al., 2019; Shehabeldeen et al., 2019), and random vector functional link (Abd Elaziz et al., 2020; Shehabeldeen et al., 2020), to predict the mechanical properties of the developed composite.

\subsection{Impact test}

The impact strength of all investigated composites decreased when the GF fraction increased, as shown in Fig. 3. For all GF total fractions, rubber-free composites have the lowest impact strength, followed by PP/GF15 R, while PP/GF10 R has the highest impact strength. For low GF fractions, a sharp reduction in the impact strength is observed, as the impact strength decreased by about $42 \%, 30 \%$, and $36 \%$ in case of the PP/GF rubber-free composite, PP/GF10 R composite, and PP/GF15 R composite, respectively, by increasing the fraction of GF by $0.05 \%$ compared with the original composite. This dramatic decrease in the impact strength is due to existence of the GF in PP, which increases the resistance to the plastic deformation and, consequently, impairs the toughness strength of the developed composites and converts it into brittle materials. Adding rubber powder to the composite results in a gradual increase in the impact strength, as rubber particles are flexible material that act as elastic shock absorbers. Thus, rubber powder could be used to treat the side effects of GF on the impact strength of the composites.

\subsection{Wear test}

The wear tests were carried out on a pin-on-disc tribometer under a constant sliding speed of $68 \mathrm{~mm}$ per second and two applied loads ( 1 and $5 \mathrm{~kg}$ ). The weight loss was calculated for pure PP and all PP/GF R composites. It is observed that weight loss decreases gradually by increasing the rubber powder content, but it begins to increase by increasing rubber powder in the sample as shown in Fig. 4. The weight loss for all investigated samples is less than that of pure PP. For all samples, including PP, the weight loss increased by about $280 \%-300 \%$ when the applied load changes from 1 to $5 \mathrm{~kg}$. 


\subsection{Microstructure}

The morphology of the fracture surfaces of impact test specimens is captured using JSM-IT100 SEM. Figure 5a shows the morphology of pure PP, while Fig. $5 b$ and $c$ show the good distribution of rubber particles and GF in the PP composite, with a reasonable adhesion. The rubber particles and PP/GF composite are well mixed, which indicates the efficient preparation process used in preparing PP composites. The rubber particles were well gilded with the PP/GF composite for different rubber particle fractions, as indicated in Fig. 6. The GF were observed to be erected from the fracture surface, while GF holes were observed on the fracture surface, which indicates the preceding breaking up of GF under applied loads which pulled the fibers outside the samples. The existence of the PP and rubber on the fiber surface revealed the good adhesion between the GF, PP, and the rubber particles. More investigations should be carried out to obtain the optimal concentration of rubber and GF additives on the mechanical properties of the produced composite by applying different metaheuristic optimization approaches (Deng et al., 2020a, b, c; Elsheikh and Abd Elaziz, 2019; Essa et al., 2020; Oliva et al., 2019; Song et al., 2021; Zayed et al., 2020).

\section{Conclusions}

PP was mixed mechanically with GF and rubber powder and then injected into the plastic injection mold. The mechanical properties of the developed PP composites were investigated using the tension test, impact test, and wear test. The microstructure and morphology of the composites were examined using a scanning electron microscope. The ultimate tensile strength of PP/GF-R composites was increased by increasing the GF weight fraction. The ultimate tensile strength was mostly increased to $34 \mathrm{MP}$ in case of PP/GF10, which is higher than that of pure PP by about $21 \%$. Rubber powder could be used to enhance the elongation of the developed composite with fewer side effects on the ultimate tensile strength. The impact strength of rubber-reinforced composites is higher than rubber-free composites. Increasing the weight fraction of GF results in a dramatic decrease in the impact strength due to the existence of the GF in PP, which increases the resistance to the plastic deformation and, consequently, impairs the toughness strength of the developed composites and converts it into brittle materials. Adding rubber powder to the composite results in a gradual increase in the impact strength, as rubber particles are flexible material that act as elastic shock absorbers. Thus, rubber powder could be used to treat the side effects of GF on the impact strength of the composites. The PP/GF composites showed better wear properties compared with pure PP, as the weight loss of the PP/GF is lower than that of pure PP. However, adding rubber powder to PP/GF composites may impair its wear properties.
Data availability. All data generated or analyzed during this study are included in this published article (see Fig. 2).

Author contributions. MD and MR conceived of the presented idea. AME carried out the experiments. AHE analyzed the results and wrote the paper.

Competing interests. The authors declare that they have no conflict of interest.

Review statement. This paper was edited by Kheng Lim Goh and reviewed by Ahmed $\mathrm{O}$. Omar and one anonymous referee.

\section{References}

Abd Elaziz, M., Shehabeldeen, T. A., Elsheikh, A. H., Zhou, J., Ewees, A. A., and Al-qaness, M. A. A.: Utilization of Random Vector Functional Link integrated with Marine Predators Algorithm for tensile behavior prediction of dissimilar friction stir welded aluminum alloy joints, Journal of Materials Research and Technology, 9, 11370-11381, 2020.

Abdellah, M. Y., Fathi, H. I., Abdelhaleem, A. M. M., and Dewidar, M.: Mechanical Properties and Wear Behavior of a Novel Composite of Acrylonitrile-Butadiene-Styrene Strengthened by Short Basalt Fiber, Journal of Composites Science, 2, 34, https://doi.org/10.3390/jcs2020034, 2018.

Ayrilmis, N., Jarusombuti, S., Fueangvivat, V., Bauchongkol, P., and White, R. H.: Coir fiber reinforced polypropylene composite panel for automotive interior applications, Fiber. Polym., 12, 919, https://doi.org/10.1007/s12221-011-0919-1, 2011.

Babikir, H. A., Elaziz, M. A., Elsheikh, A. H., Showaib, E. A., Elhadary, M., Wu, D., and Liu, Y.: Noise prediction of axial piston pump based on different valve materials using a modified artificial neural network model, Alexandria Engineering Journal, 58, 1077-1087, 2019.

Barré, S. and Benzeggagh, M. L.: On the use of acoustic emission to investigate damage mechanisms in glass-fibre-reinforced polypropylene, Compos. Sci. Technol., 52, 369-376 1994.

Carvalho, G. B., Canevarolo, S. V., and Sousa, J. A.: Influence of interfacial interactions on the mechanical behavior of hybrid composites of polypropylene/short glass fibers/hollow glass beads, Polym. Test., 85, 106418, https://doi.org/10.1016/j.polymertesting.2020.106418, 2020.

Deng, W., Xu, J., Gao, X. Z., and Zhao, H.: An Enhanced MSIQDE Algorithm With Novel Multiple Strategies for Global Optimization Problems, IEEE T. Syst. Man Cyb., 1-10, https://doi.org/10.1109/TSMC.2020.3030792, 2020a.

Deng, W., Xu, J., Song, Y., and Zhao, H.: Differential evolution algorithm with wavelet basis function and optimal mutation strategy for complex optimization problem, Appl. Soft Comput., 100, 106724, https://doi.org/10.1016/j.asoc.2020.106724, 2020b.

Dewidar, M., Abdel-Jaber, G., Bakrey, M., and Badry, H.: Effect of Processing Parameters and amount of additives on the Mechanical Properties and Wear Resistance of Copper-based Composite, 
International Journal of Mechanical and Mechatronics Engineering, 10, 20-26, 2010.

Deng, W., Xu, J., Zhao, H., and Song, Y.: A Novel Gate Resource Allocation Method Using Improved PSO-Based QEA, IEEE T. Intell. Transp., 1-9, https://doi.org/10.1109/TITS.2020.3025796, 2020c.

El-Kassas, A. M. and Elsheikh, A. H.: A new eco-friendly mechanical technique for production of rice straw fibers for medium density fiberboards manufacturing, Int. J. Environ. Sci. Te., 2020.

El-Said, E. M. S., Abd Elaziz, M., and Elsheikh, A. H.: Machine learning algorithms for improving the prediction of air injection effect on the thermohydraulic performance of shell and tube heat exchanger, Appl. Therm. Eng., 185, 116471, https://doi.org/10.1016/j.applthermaleng.2020.116471, 2021.

Elaziz, M. A., Elsheikh, A. H., and Sharshir, S. W.: Improved prediction of oscillatory heat transfer coefficient for a thermoacoustic heat exchanger using modified adaptive neuro-fuzzy inference system, Int. J. Refrig., 102, 47-54, 2019.

Elsheikh, A. H. and Abd Elaziz, M.: Review on applications of particle swarm optimization in solar energy systems, Int. J. Environ. Sci. Technol., 16, 1159-1170, 2019.

Elsheikh, A. H., Deng, W., and Showaib, E. A.: Improving laser cutting quality of polymethylmethacrylate sheet: experimental investigation and optimization, Journal of Materials Research and Technology, 9, 1325-1339, https://doi.org/10.1016/j.jmrt.2019.11.059, 2019a.

Elsheikh, A. H., Sharshir, S. W., Abd Elaziz, M., Kabeel, A. E., Guilan, W., and Haiou, Z.: Modeling of solar energy systems using artificial neural network: A comprehensive review, Sol. Energy, 180, 622-639, 2019b.

Elsheikh, A. H., Abd Elaziz, M., Babikir, H. A., Wu, D., and Liu, Y.: A new artificial neural network model integrated with a cat swarm optimization algorithm for predicting the emitted noise during axial piston pump operation, IOP Conf. Ser.-Mat. Sci., 973, 012035, https://doi.org/10.1088/1757-899x/973/1/012035, 2020a.

Elsheikh, A. H., Shehabeldeen, T. A., Zhou, J., Showaib, E., and Abd Elaziz, M.: Prediction of laser cutting parameters for polymethylmethacrylate sheets using random vector functional link network integrated with equilibrium optimizer, J. Intell. Manuf., https://doi.org/10.1007/s10845-020-01617-7, 2020 b.

Elsheikh, A. H., Yu, J., Sathyamurthy, R., Tawfik, M. M., Shanmugan, S., and Essa, F. A.: Improving the tribological properties of AISI M50 steel using Sns/Zno solid lubricants, J. Alloy. Compd., 821, 153494, https://doi.org/10.1016/j.jallcom.2019.153494, 2020c.

Elsheikh, A. H., Katekar, V. P., Muskens, O. L., Deshmukh, S. S., Elaziz, M. A., and Dabour, S. M.: Utilization of LSTM neural network for water production forecasting of a stepped solar still with a corrugated absorber plate, Process Saf. Environ., 148, 273-282, 2021

Essa, F. A., Abd Elaziz, M., and Elsheikh, A. H.: An enhanced productivity prediction model of active solar still using artificial neural network and Harris Hawks optimizer, Appl. Therm. Eng., 170, 115020, https://doi.org/10.1016/j.applthermaleng.2020.115020, 2020.

Essa, F. A., Elsheikh, A. H., Yu, J., Elkady, O. A., and Saleh, B.: Studies on the effect of applied load, sliding speed and temperature on the wear behavior of M50 steel reinforced with $\mathrm{Al}_{2} \mathrm{O}_{3}$ and/or graphene nanoparticles, Journal of Materials Research and Technology, 12, 283-303, https://doi.org/10.1016/j.jmrt.2021.02.082, 2021.

Etcheverry, M. and Barbosa, S. E.: Glass fiber reinforced polypropylene mechanical properties enhancement by adhesion improvement, Materials, 5, 1084-1113, 2012.

Fadl, A. E., Jingui, Y., Ammar, H. E., and Tawfik, M. M.: A new M50 matrix composite sintered with a hybrid Sns/Zno nanoscale solid lubricants: an experimental investigation, Mater. Res. Express, 6, 116523, https://doi.org/10.1088/2053-1591/ab4675, 2019.

Huang, L., Wu, Q., Li, S., Ou, R., and Wang, Q.: Toughness and crystallization enhancement in wood fiber-reinforced polypropylene composite through controlling matrix nucleation, J. Mater. Sci., 53, 6542-6551, 2018.

Ismail, H. and Suryadiansyah, S.: Effects of Filler Loading on Properties of Polypropylene-Natural Rubber-Recycle Rubber Powder (PP-NR-RRP) Composites, J. Reinf. Plast. Comp., 23, 639650, 2004.

Kamal, A., Elsheikh, A. H., and Showaib, E.: Pre-Cracking techniques of polymeric materials: an overview, IOP Conf. Ser.-Mat. Sci., 973, 012028, https://doi.org/10.1088/1757899x/973/1/012028, 2020.

Karmarkar, A., Chauhan, S. S., Modak, J. M., and Chanda, M.: Mechanical properties of wood-fiber reinforced polypropylene composites: Effect of a novel compatibilizer with isocyanate functional group, Compos. Part A-Appl. S., 38, 227-233, 2007.

Khoshaim, A. B., Elsheikh, A. H., Moustafa, E. B., Basha, M., and Mosleh, A. O.: Prediction of Residual Stresses in Turning of Pure Iron using Artificial Intelligence-based Methods, Journal of Materials Research and Technology, 11, 2181-2194, https://doi.org/10.1016/j.jmrt.2021.02.042, 2021a.

Khoshaim, A. B., Elsheikh, A. H., Moustafa, E. B., Basha, M., and Showaib, E. A.: Experimental investigation on laser cutting of PMMA sheets: Effects of process factors on kerf characteristics, Journal of Materials Research and Technology, 11, 235-246, https://doi.org/10.1016/j.jmrt.2021.01.012, 2021 b.

Lin, J.-H., Huang, C.-L., Liu, C.-F., Chen, C.-K., Lin, Z.-I., and Lou, C.-W.: Polypropylene/short glass fibers composites: effects of coupling agents on mechanical properties, thermal behaviors, and morphology, Materials, 8, 8279-8291, 2015.

Liu, Q., Huang, G., and Xu, Y.: Investigation of drilling 2D Cf / CSiC composites with brazed diamond core drills, Mech. Sci., 11, 349-356, https://doi.org/10.5194/ms-11-349-2020, 2020.

Luo, G., Liu, G., Chen, Y., Liang, W., Liu, G., Niu, Y., and Li, G.: High performance glass fiber reinforced polypropylene realized by reactive extrusion technology, Compos. Sci. Technol., 165, 198-205, 2018.

Mohan, T. P. and Kanny, K.: Influence of nanoclay on rheological and mechanical properties of short glass fiber-reinforced polypropylene composites, J. Reinf. Plast. Comp., 30, 152-160, 2010.

Morfologi, S. and Mekanik, T.: Glass fiber and nanoclay reinforced polypropylene composites: Morphological, thermal and mechanical properties, Sains Malaysiana, 42, 537-546, 2013.

Oksman, K., Mathew, A. P., Långström, R., Nyström, B., and Joseph, K.: The influence of fibre microstructure on fibre breakage and mechanical properties of natural fibre reinforced polypropylene, Compos. Sci. Technol., 69, 1847-1853, 2009. 
Oliva, D., Elaziz, M. A., Elsheikh, A. H., and Ewees, A. A.: A review on meta-heuristics methods for estimating parameters of solar cells, J. Power Sources, 435, 126683, https://doi.org/10.1016/j.jpowsour.2019.05.089, 2019.

Ovcharenko, V. G. and Bashtannik, P. I.: Polypropylene reinforced with aramid and glass fibers, Mech. Compos. Mater., 32, 77-80, 1996.

Padhi, A. and Sahoo, D.: Mechanical Characterization of Hybrid Carbon-Glass-Reinforced Polypropylene Composites, in: Advances in Computational Methods in Manufacturing, edited by: Narayanan, R. G., Joshi, S. N., and Dixit, U. S., Springer Singapore, Singapore, 783-792, 2019.

Palza, H., Vergara, R., and Zapata, P.: Composites of polypropylene melt blended with synthesized silica nanoparticles, Comp. Sci. Technol., 71, 535-540, 2011.

Pasquini, N. and Addeo, A.: Polypropylene handbook, Hanser Publications, Munich, 2005.

Pozzi, P., Taurino, R., Zanasi, T., Andreola, F., Barbieri, L., and Lancellotti, I.: New polypropylene/glass composites: Effect of glass fibers from cathode ray tubes on thermal and mechanical properties, Compos. Part A-Appl. S., 41, 435-440, 2010.

Pustak, A., Denac, M., Leskovac, M., Švab, I., Musil, V., and Šmit, I.: Structure and morphology of silica-reinforced polypropylene composites modified with m-EPR copolymers, J. Polym. Res., 23, 37, 2016.

Raghu, N., Kale, A., Chauhan, S., and Aggarwal, P. K.: Rice husk reinforced polypropylene composites: mechanical, morphological and thermal properties, Journal of the Indian Academy of Wood Science, 15, 96-104, 2018.

Rahman, N. A., Hassan, A., Yahya, R., Lafia-Araga, R. A., and Hornsby, P. R.: Polypropylene/glass fiber/nanoclay hybrid composites: morphological, thermal, dynamic mechanical and impact behaviors, J. Reinf. Plast. Comp.,31, 1247-1257, 2012.

Rahman, N. A., Hassan, A., Yahya, R., and Lafia-Araga, R. A.: Impact properties of glass-fiber/polypropylene composites: The influence of fiber loading, specimen geometry and test temperature, Fiber. Polym., 14, 1877-1885, 2013.

Rasana, N. and Jayanarayanan, K.: Polypropylene/short glass fiber/nanosilica hybrid composites: evaluation of morphology, mechanical, thermal, and transport properties, Polym. Bull., 75, 2587-2605, 2018.

Rasana, N., Jayanarayanan, K., Deeraj, B. D. S., and Joseph, K.: The thermal degradation and dynamic mechanical properties modeling of MWCNT/glass fiber multiscale filler reinforced polypropylene composites, Compos. Sci. Technol., 169, 249259, 2019

Rathod, V. T., Kumar, J. S., and Jain, A.: Polymer and ceramic nanocomposites for aerospace applications, Appl. Nanosci., 7, 519-548, 2017.

Saba, A. I. and Elsheikh, A. H.: Forecasting the prevalence of COVID-19 outbreak in Egypt using nonlinear autoregressive artificial neural networks, Process Saf. Environ., 141, 1-8, 2020.

Santulli, C., Brooks, R., Long, A. C., Warrior, N. A., and Rudd, C. D.: Impact properties of compression moulded commingled E-glass-polypropylene composites, Plast. Rubber Compos., 31, 270-277, 2002.

Shazed, M. A., Suraya, A. R., Rahmanian, S., and Mohd Salleh, M. A.: Effect of fibre coating and geometry on the tensile prop- erties of hybrid carbon nanotube coated carbon fibre reinforced composite, Mater. Design, 54, 660-669, 2014.

Shehabeldeen, T. A., Elaziz, M. A., Elsheikh, A. H., and Zhou, J.: Modeling of friction stir welding process using adaptive neurofuzzy inference system integrated with harris hawks optimizer, Journal of Materials Research and Technology, 8, 5882-5892, 2019.

Shehabeldeen, T. A., Elaziz, M. A., Elsheikh, A. H., Hassan, O. F., Yin, Y., Ji, X., Shen, X., and Zhou, J.: A Novel Method for Predicting Tensile Strength of Friction Stir Welded AA6061 Aluminium Alloy Joints Based on Hybrid Random Vector Functional Link and Henry Gas Solubility Optimization, IEEE Access, 8, 79896-79907, 2020.

Showaib, E. A. and Elsheikh, A. H.: Effect of surface preparation on the strength of vibration welded butt joint made from PBT composite, Polym. Test., 83, 106319, https://doi.org/10.1016/j.polymertesting.2019.106319, 2020.

Shubhra, Q. T., Alam, A., and Quaiyyum, M.: Mechanical properties of polypropylene composites: A review, J. Thermoplast. Compos., 26, 362-391, 2013.

Song, Y., Wu, D., Deng, W., Gao, X.-Z., Li, T., Zhang, B., and Li, Y.: MPPCEDE: Multi-population parallel co-evolutionary differential evolution for parameter optimization, Energy Convers. Manage., 228, 113661, https://doi.org/10.1016/j.enconman.2020.113661, 2021

Strapasson, R., Amico, S. C., Pereira, M. F. R., and Sydenstricker, T. H. D.: Tensile and impact behavior of polypropylene/low density polyethylene blends, Polym. Test., 24, 468-473, 2005.

Wang, Y. and Fu, Z.: Analytical Study of Babbitt/steel Composite Structural Bars in Oblique Contact-impact with a Solid Flat Surface, Mech. Sci., 10, 213-228, https://doi.org/10.5194/ms10-213-2019, 2019.

Weiss, R. A.: Mechanical properties of polypropylene reinforced with short graphite fibers, Polym. Composite., 2, 95-101, 1981.

Xu, P., Qu, M., Ning, Y., Jia, T., Zhang, Y., Wang, S., Feng, N., and $\mathrm{Wu}, \mathrm{L}$. : High performance and low floating fiber glass fiberreinforced polypropylene composites realized by a facile coating method, Advanced Composites and Hybrid Materials, 2, 234241, 2019.

$\mathrm{Xu}$, S., Ferraris, A., Airale, A. G., and Carello, M.: Elastokinematics design of an innovative composite material suspension system, Mech. Sci., 8, 11-22, https://doi.org/10.5194/ms-811-2017, 2017.

Yimit, M., Ni, L., Du, Y., and Bkan, R.: Mechanical and Aging Properties of Polypropylene and Styrene-Butadiene-Styrene Composites Under Outdoor and Indoor Conditions, Strength Mater., 50, 788-799, 2018.

Zayed, M. E., Zhao, J., Elsheikh, A. H., Li, W., and Elaziz, M. A.: Optimal design parameters and performance optimization of thermodynamically balanced dish/Stirling concentrated solar power system using multi-objective particle swarm optimization, Appl. Therm. Eng., 178, 115539, https://doi.org/10.1016/j.applthermaleng.2020.115539, 2020. 